\title{
Heat Transfer Enhancement In a Cylindrical Finned Heat Exchanger: Superior Blocks Positions
}

\author{
Sara Touzani, Abdelkhalek Cheddadi, Mohammed Touhami Ouazzani \\ Research Team "Energy Systems, Mechanical Structures and Materials, and Modeling of Industrial Processes", MOSEM2PI \\ Mohammadia School of Engineers, Mohammed V University in Rabat, Morocco. \\ sara.touz@gmail.com; cheddadi@emi.ac.ma; ouazzani@emi.ac.ma
}

\section{Extended Abstract}

Tubular heat exchangers are widely used in different industries for both cooling and heating processes. They are known by their resistance to high pressures and temperatures. However, their performance compared to other heat exchangers types can be low. In order to improve their performance, many studies were carried out [1]. It was shown by [2] that adding fins adequately increases the surface area to achieve the required heat transfer rate. Many fins parameters were studied such as fins shapes, height and position $[3,4,5]$.

Our heat exchanger is modelled as a horizontal cylindrical annulus containing two isothermal blocks placed on the upper part of the inner cylinder. The blocks position impact on heat transfer and flow structure is numerically investigated using Finite Difference Method with ADI scheme. Taking into account the symmetry of the problem, the streamlines and isotherms are represented in the half of the cavity. The simulation is carried out for Rayleigh numbers range, $R a$, varying between 1000 and 10000 and the blocks dimensionless height and width, $h=0.5$ and $l=0.109$ respectively. The studied blocks positions are $0.79 \pi, 0.82 \pi, 0.87 \pi$ and $0.91 \pi$.

The flow structure observed is a multicellular regime for all these positions. The heat transfer rate is quantified by the Nusselt number. The three positions $0.79 \pi, 0.82 \pi$ and $0.87 \pi$ give a slightly similar Nusselt number greater than the one obtained in position $0.91 \pi$, for $R a<3500$. Beyond this value, Nusselt number decreases with the blocks position increase, showing that the position $0.79 \pi$ enhances heat transfer better than the other positions. In fact, by choosing the position $0.79 \pi$ instead of $0.91 \pi$, we obtain a gain in heat transfer increasing from $1.32 \%$ at $R a=3500$ to $7.47 \%$ at $R a=10000$.

\section{References}

[1] H. K. Dawood, H. A. Mohammed, N. A. Che Sidik, K. M. Munisamy, M. A. Wahid, "Forced, natural and mixedconvection heat transfer and fluid flow annulus: A review," Int. Comm. Heat Mass Transfer, vol. 62, pp. 45-57, 2015.

[2] N. Nagarani, K. Mayilsamy, A. Murugesan, G. S. Kumar, "Review of utilization of extended surfaces in heat transfer problems," Renewable and Sustainable Energy Reviews, vol. 29, pp. 604-613, 2014.

[3] S. Kumar, K. V. Karanth, K. Murthy, "Numerical study of heat transfer in a finned double pipe heat exchanger," WJMS, vol. 11, no.1, pp. 43-54, 2015.

[4] A. Idrissi, A. Cheddadi, M. T. Ouazzani, "Heat transfer in an annular space fitted with heating isothermal blocks: Numerical bifurcation for low blocks height," Case Stud. Therm. Eng., vol. 7, pp. 1-7, 2016.

[5] T. Stamboul, M. Ait Saada, A. Campo, "Maximum heat transfer reduction in a horizontal porous annular cavity induced by the attachment of symmetric radial baffles to the hot inner cylinder," App. Therm. Eng., vol. 93, pp.1105- 1113, 2016. 